\title{
PAULO FREIRE, LEITOR DE MARX: NEXOS ENTRE POLÍTICA, EDUCAÇÃO E EMANCIPAÇÃO ${ }^{1}$ \\ Renato Kendy Hidaka
}

\section{RESUMO}

Este artigo analisa o modo como se estabelece a relação entre política, educação e emancipação no pensamento de Paulo Freire. Procura mostrar que, para esse autor, existe uma relação necessária entre política e educação - que marca profundamente suas obras, embora o mesmo não ocorra entre educação e emancipação. Ao tratar este último binômio como uma relação possível e não necessária, Freire atenta para o elemento essencial que tensiona os dois termos: o engajamento social.

Palavras-chave: Paulo Freire; Política; Educação; Emancipação

\section{PAULO FREIRE, READER OF MARX: CONNECTIONS BETWEEN POLITICS, EDUCATION AND EMANCIPATION.}

\begin{abstract}
This article analyzes the relationship established between politics, education and emancipation in the Paulo Freire's thought. Seeks to show that for this author there is a necessary relationship between politics and education - that deeply marks his works, although this does not occur between education and emancipation. In our view, by treating the latter binomial as a relationship possible and not necessary, Freire regards the essential element that unites the two terms: the bond of social engagement.
\end{abstract}

Key words: Paulo Freire; Politics; Education; Emancipation

1 Registre-se aqui minha enorme gratidão à Prof. ${ }^{a}$ Dr. ${ }^{a}$ Valdelúcia Alves da Costa, pelas estimulantes observações críticas e sugestões feitas a este texto. 
Quando muito moço, muito jovem, eu fui aos mangues do Recife, aos córregos do Recife, aos morros do Recife, às zonas rurais de Pernambuco trabalhar com os camponeses, com as camponesas, com os favelados. Eu confesso, sem nenhuma churumingas, eu confesso que fui até lá movido por uma certa lealdade ao Cristo de quem eu era mais ou menos camarada. Mas o que acontece é que, quando eu chego lá, a realidade dura dos favelados, a realidade dura do camponês, a negação do seu ser como gente, a tendência àquela adaptação, aquele estado quase inerte diante da negação da liberdade... Aquilo tudo me remeteu a Marx. Eu sempre digo, não foram os camponeses que disseram a mim: Paulo, tu já lestes Marx? Não, de jeito nenhum. Eles não liam nem jornal! Foi a realidade deles que me remeteu a Marx. E eu fui a Marx.

(Paulo Freire, última entrevista, realizada em 17 de abril de 1997, à Luciana Burlamaqui) ${ }^{2}$

\section{Introdução}

Este texto analisa a relação entre política, educação e emancipação no pensamento de Paulo Freire. A hipótese aqui defendida é a de que, para esse autor, há uma relação necessária estabelecida entre política e educação, embora o mesmo não ocorra entre os termos educação e emancipação. A nosso ver, ao tratar este último binômio como uma relação não necessária do ponto de vista lógico -, tal autor põe em evidência o potencial emancipatório da prática educativa, decorrente da articulação possível entre esses termos, tensionados, na prática, pelo laço de engajamento social.

É importante dizer que isso não significa que a prática educativa transforme por si só a realidade, e sim que ela pode contribuir para a ampliação da compreensão do mundo dos agentes que nela estão envolvidos. Tributário das contribuições teóricas de Marx, Paulo Freire compreende que a transformação qualitativa da sociedade só se realiza mediante a alteração das condições materiais objetivas, que se dá, por sua vez, através da práxis humana coletiva: a luta de classes.

\section{A relação entre política e educação}

Uma das teses centrais do pensamento freireano consiste na defesa da relação intrínseca entre política e educação. Essa tese - esclareça-se desde já - não deve ser interpretada de forma simplista, o que significa portanto que a compreensão de um dos termos

\footnotetext{
${ }^{2}$ Vídeo disponível em: 〈http://www.youtube.com/watch?v=pSyaZAWIr1I>. Acesso: 07/03/2011.
} 
não se esgota na compreensão do outro. Ou seja, tanto a política quanto a educação podem ser apreendidas enquanto esferas de atuação ou áreas de conhecimento distintas, passíveis de serem analisadas como objetos específicos em sua autonomia relativa uma da outra. Ao afirmar que há entre a política e a educação uma relação intrínseca, a intenção de Paulo Freire é evidenciar fundamentalmente, por um lado, a natureza política do processo educativo bem como, por outro, o caráter educativo do ato político. Sua intenção é salientar a tensão entre esses termos, mostrando que do mesmo modo que não há prática política esvaziada de significado educativo também não há educação neutra.

Considerando essa relação entre política e educação, Paulo Freire denominará de ingênua a visão que procura negar a natureza política do processo educativo (visão essa inclinada a conceber a educação como um quefazer puro, a serviço da "humanidade") e contrapõe-se sustentando que a educação, além de ser realizada num dado tempo-espaço, é realizada com e por indivíduos históricos. Para que fique mais claro, diremos que em formações sociais onde predomina o modo de produção capitalista, os homens agem no interior de totalidade estruturada que é determinada, em última instância, ${ }^{3}$ pelas relações de produção, caracterizadas pelo antagonismo entre capital e trabalho. Assim sendo, ocupam necessariamente um lugar nessa relação, personificando uma dessas categorias. Os homens agem determinados, portanto, ou pela sua situação de detentores de meios de produção e de acumuladores de capital (caso em que assumem a condição de exploradores) ou de despojamento desses meios produção e, por conseguinte, de vendedores de força de trabalho

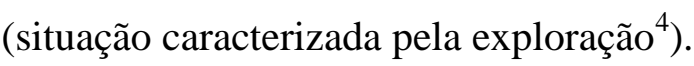

Se todos os indivíduos se encontram no mundo ocupando lugares determinados nas relações de produção e, consequentemente, na divisão social do trabalho, tem-se como corolário que as práticas sociais não são neutras, uma vez que sofrem os efeitos da determinação das estruturas da totalidade social. Daí que, conforme Paulo freire, uma das questões fundamentais colocadas no processo educativo ser a clareza em torno de a favor de quem e do quê ou contra quem e contra o quê se destina a educação. Afinal, atuará o educador a favor dos que oprimem ou dos que são oprimidos? Lutará pela manutenção da ordem dos que exploram ou pela libertação dos explorados?

\footnotetext{
${ }^{3}$ Entenda-se que há portanto outras determinações agindo no interior da totalidade social. No Prefácio de Para a Crítica da Economia Política, Marx assinala que sobre as relações de produção se erige uma superestrutura jurídico-política e ideológica que sobredetermina a totalidade social.

${ }^{4}$ Afirmar que os proletários e outros assalariados são condicionados pela sua situação de despojamento de meios de produção significa, sobretudo, que eles são levados a comparecer "sozinhos" (sem necessidade de repressão física) no mercado de trabalho em troca de salário para assegurar a sua sobrevivência.
} 
Diante dessa questão, Paulo Freire aponta que uma das tarefas dos que se engajam na causa dos oprimidos consiste na desnaturalização da forma social presente, na contraposição aos discursos ideológicos conservadores que naturalizam as desigualdades, apresentando a realidade de forma estanque e fatalista. Sob o efeito da ideologia dominante, esse tipo de discurso é interiorizado e propalado inclusive por aqueles que sofrem a opressão. Não é raro ouvirmos de membros das camadas populares coisas do tipo: "o mundo é assim mesmo!" ou ainda, "política é coisa que não se discute!", entre tantas outras.

Imersos nesse tipo de visão, que separa radicalmente política de educação, tais indivíduos trazem consigo uma concepção de educação recoberta pelo manto da neutralidade. Paulo Freire observa que tal visão é funcional aos opressores, que tem interesse no ocultamento da realidade e na manutenção do status quo; mas, inversamente, é prejudicial aos oprimidos, já que cria entraves à emergência da consciência de classe e à organização da luta pela emancipação.

A respeito da relação entre consciência e luta de classes, o professor de Economia Política, José Luís Fiori, assinala:

A ação libertadora implica num momento necessariamente consciente e volitivo [...] A ação dominadora, entretanto, não supõe esta dimensão com a mesma necessariedade, pois a própria funcionalidade mecânica e inconsciente da estrutura é mantenedora de si mesma e, portanto, da dominação (1987, p.21)

Esse trecho, constante na obra Pedagogia do Oprimido, é complementado por Paulo Freire que, entre outras coisas, enuncia: "Se os homens são os produtores desta realidade e se esta, na 'inversão da práxis', se volta sobre eles e os condiciona, transformar a realidade opressora é tarefa histórica, é tarefa dos homens”. Esta transformação só é possível prossegue - porque a "desumanização, mesmo que um fato concreto na história, não é, porém, destino dado, mas resultado de uma 'ordem' injusta que gera a violência dos opressores e esta, o ser menos" (op.cit, p.16).

\section{Educação e emancipação}

Se entre os termos educação e política há uma relação necessária, o mesmo já não ocorre com o binômio educação/emancipação. Do ponto de vista lógico, a relação que se estabelece entre esses dois termos é uma relação de possibilidade, vale dizer, pode ou não ocorrer, e não de necessidade. Daí constatarmos a coexistência tanto de práticas educativas libertadoras quanto de práticas educativas conservadoras. 
As obras de Paulo Freire podem ser interpretadas, seguindo esse raciocínio, como uma tentativa, no plano teórico, de explicitar a tensão entre os termos mencionados, revelando assim as possibilidades e o potencial libertador das práticas educativas. ${ }^{5}$ Esse tensionamento terá sua expressão, em termos práticos, no engajamento social consciente dos atores no processo educativo com vistas à libertação dos "oprimidos".

Paulo Freire detecta que, embora existam educadores de boa vontade engajados na luta pela causa dos oprimidos, muitos deles acabam involuntariamente contribuindo à manutenção da dominação que, em tese, pretendem combater. Isso porque em sua atuação prática eles se mantêm adeptos de uma concepção de bancária de educação. Ou seja, permanecem reféns de concepção de prática educativa que confere aos educadores a posição de sujeitos (considerados os detentores do conhecimento) e aos educandos, a posição de objetos, de depósitos de saber passivos.

Contratriando a postura do educador bancário ${ }^{6}$, Paulo Freire defende que o educador crítico, comprometido com a prática educacional libertadora:

[...] precisa reconhecer, primeiro, nos educandos em processo de saber mais, os sujeitos, com ele, deste processo e não pacientes acomodados; segundo, reconhecer que o conhecimento não é um dado aí, algo imobilizado, concluído, terminado, a ser transferido por quem o adquiriu a quem não o adquiriu. (1997a, p.29)

A passagem acima sugere, portanto, que uma das premissas da pedagogia do oprimido é o reconhecimento do educando como também um sujeito-agente do processo educativo. Reconhecimento esse que vai desde a identificação daquele como um sujeito concreto sujeito que tem necessidades (biológicas e históricas ${ }^{7}$ ), que é movido por interesses, que faz escolhas, que age com intencionalidade e dá sentido humano ao mundo - à percepção de sua inserção no interior de uma totalidade social mais ampla, permeada pela luta de classes.

No limite, para Paulo Freire, reconhecer a inserção do educador e do educando na luta de classes é reconhecer sua posição na luta entre opressores e oprimidos ${ }^{8}$. Consoante a isso,

\footnotetext{
${ }^{5}$ Deve-se enunciar, contudo, que as reflexões do autor não são fruto de devaneios intelectuais, nem resultam apenas de leituras (por mais importantes que estas tenham sido), conforme ele mesmo indica. Tais reflexões estão sempre ancoradas em situações reais, são a expressão de investigações de anos, fundamentadas em trabalhos educativos concretos realizados com diversos grupos pertencentes às classes populares.

${ }^{6}$ Em Escola e Democracia, Dermaval Saviani sugere que Paulo Freire, ao contrapor-se à pedagogia tradicional (centrada na figura do professor e na transmissão de conteúdos), acabou por desenvolver no Brasil nada mais que uma variante do escola-novismo, uma espécie de "Escola Nova Popular" (19--,p.12)

${ }^{7}$ Note-se que as necessidades históricas são variáveis. Nos Manuscritos econômico-filosóficos, Marx sublinha que a fome satisfeita por carne cozida, com a utilização de garfo e faca é diferente da fome saciada com a ajuda das mãos, unhas e dentes para comer carne crua.

${ }^{8}$ Os termos opressores e oprimidos também são utilizados por Marx. No Manifesto do Partido Comunista, ele e Engels assim caracterizam a História das sociedades até aquele momento: "Homem livre e escravo, patrício e plebeu, barão e servo, membro das corporações e aprendiz, em suma, opressores e oprimidos, estiveram em
} 
Freire aponta que em muitos casos o educando sujeito-agente encontra-se, em sua situação existencial, preponderantemente um sujeito-sujeitado, adaptado em sua situação de opressão. A respeito dessa adaptação das classes populares às estruturas dominantes, Freire diz:

\begin{abstract}
Os oprimidos, contudo, acomodados e adaptados, "imersos" na própria engrenagem da estrutura dominadora, temem a liberdade, enquanto não se sentem capazes de correr o risco de assumi-la. E temem, também, na medida em que, lutar por ela, significa uma ameaça, não só aos que a usam para oprimir, como seus "proprietários" exclusivos, mas aos companheiros oprimidos, que se assustam com maiores repressões (idem, p. 19)
\end{abstract}

Os oprimidos, continua o autor:

Sofrem uma dualidade que se instala na "interioridade" do seu ser. Descobrem que, não sendo livre, não chegam a ser autenticamente. Querem ser, mas temem ser. São eles e ao mesmo tempo o outro introjetado neles, como consciência opressora. Sua luta se trava entre serem eles mesmos ou serem duplos. Entre expulsarem ou não ao opressor de "dentro" de si. Entre se desalienarem ou se manterem alienados. Entre seguirem prescrições ou terem opções. Entre serem espectadores ou atores. Entre atuarem ou terem a ilusão de que atuam, na atuação dos opressores. Entre dizerem a palavra ou não terem voz, castrados no seu poder de criar e recriar, no seu poder de transforma o mundo. (op. cit)

Daí para Paulo Freire a importante função do educador crítico que, enquanto um “organizador necessário, é ensinante e um desafiador”. Através dos efeitos contraditórios produzidos pela realidade opressora, o educador crítico problematiza, com o educando, a sua situação existencial concreta, apresentando-a como problema que, por sua vez, o desafia e, assim, lhe exige resposta.

Não se trata de "falar ao povo sobre a nossa visão de mundo, ou tentar impô-la a ele [caso em que se permaneceria na concepção bancária de educação], mas dialogar com ele sobre a sua visão do mundo, que se manifesta nas várias formas de sua ação, reflete a sua situação no mundo, em que se constitui” (idem, p.49). Colocando de outro modo, não se trata de falar ao ou sobre a vida do "povo", mas sim de ouvi-los para falar com eles: "Pretender a libertação deles [dos oprimidos] sem a sua reflexão no ato desta libertação é transformá-los em objeto que devesse salvar de um incêndio. É fazê-los cair no engodo populista e transformá-los em massa de manobra”. (1997, p.29).

$\mathrm{Na}$ perspectiva freireana o educador está, desse modo, envolvido no processo de formação para a autonomia dos sujeitos, algo que é praticamente ausente das práticas educativas conservadoras, voltadas exclusivamente para a adaptação à produção e reprodução

contraposição uns aos outros e envolvidos numa luta ininterrupta, ora disfarçada, ora aberta, que terminou sempre com a transformação revolucionária da sociedade interira ou com o declínio conjunto das classes em conflito (2008, p.8, grifo nosso) 
social. Assim, na pedagogia do oprimido, o próprio papel da educação na conservação/reprodução social é problematizado.

Enquanto prática realizada no interior de uma totalidade antagônica, Paulo Freire assinala que seria uma contradição se os opressores não só defendessem, mas praticassem uma educação libertadora. Por isso, o autor faz a distinção entre "educação sistemática" e os "trabalhos educativos". A primeira consistindo nas práticas educacionais que agem dominantemente em correspondência com a manutenção das estruturas sociais, conformandose enquanto processo de subjetivação/interiorização de valores funcionais à ordem, seja qualificando os sujeitos para a esfera produtiva, seja colaborando para a reprodução da submissão às regras da ordem estabelecida (submissão à ideologia dominante). Cabe aqui, uma observação. Muitos educadores têm limitado a prática educativa libertadora à prática educativa para a cidadania. A nosso ver, analisada da perspectiva freireana, isso é um equivoco. Certamente que Paulo Freire reconhecia a importância da cidadania e da democracia burguesa, que em comparação com os regimes ditatoriais permitem um melhor desenvolvimento da organização e da luta dos oprimidos - de resto, algumas de suas obras, marcadas pela conjuntura de luta pela redemocratização do país, denotam isso. No entanto, a cidadania política não pode ser confundida com a emancipação humana ${ }^{9}$. A cidadania burguesa possibilita o reconhecimento e a conquista de direitos políticos e sociais no interior da ordem, é a participação (luta) do "povo" dentro dos limites fixados pela forma democrática do Estado burguês. Essa participação, por mais que possibilite uma melhora na condição de vida dos oprimidos, não altera a reprodução dos lugares ocupados na economia e na divisão social do trabalho, não altera, portanto, a condição de explorador/explorado característico das sociedades capitalistas.

A segunda - as "práticas educativas" - referem-se às práticas libertadoras, comprometidas com a emancipação dos oprimidos. Estas, na concepção freireana, além de comprometidas com o ensino de conteúdos também estão comprometidas com a conscientização de seus agentes. Conscientização esta que implica:

[...] que ultrapassemos a esfera espontânea de apreensão da realidade, para chegarmos a uma esfera crítica na qual a realidade se dá como objeto cognoscível e na qual o homem assume uma posição epistemológica. A conscientização é, neste sentido, um teste de realidade. Quanto mais conscientização, mais se "desvela" a realidade, mais se penetra na essência fenomênica do objeto, frente ao qual nos encontramos para analisá-lo. Por esta mesma razão, a conscientização não consiste em "estar frente à realidade" assumindo uma posição falsamente intelectual. A

\footnotetext{
${ }^{9}$ Sobre essa questão, ver a reflexão desenvolvida por Karl Marx em Para a questão judaica. São Paulo: Expressão Popular, 2009.
} 
conscientização não pode existir fora da "práxis", ou melhor, sem o ato açãoreflexão. Esta unidade dialética constitui, de maneira permanente, o modo de ser ou de transformar o mundo que caracteriza os homens. Por isso mesmo, a conscientização é um compromisso histórico. É também consciência histórica: é inserção crítica na história, implica que os homens assumam o papel de sujeitos que fazem e refazem o mundo. (FREIRE, 1989)

A consciência, acima mencionada, não deve ser compreendida de forma idealista, como se ela por si mesma modificasse a realidade, de tal maneira que a transformação social nada mais fosse do que uma transformação das consciências. A consciência a que o autor se refere é a consciência que está relacionada à análise rigorosa das condições objetivas sociais que mantém os indivíduos como sujeitos-sujeitados, e que tem um vínculo substantivo com a prática. Sem o desvelamento das condições sociais opressoras pela crítica reflexiva, não é possível prática transformadora (Lenin dizia que sem teoria revolucionária não é possível prática revolucionária). A consciência crítica dos oprimidos reclama pela transformação social, que só pode ocorrer pela prática - a prática material se coloca assim como uma necessidade para a transformação.

Isso porque a mera crítica à sociedade burguesa, reconhecimento da realidade que não leve a inserção crítica (ação já) não conduz à transformação material objetiva, e tende a reproduzir as relações sociais na forma, na medida em que se realiza em conformidade com a organização político-ideológica burguesa, alicerçada numa integração social vertical marcada por relações de dominação/subordinação. Por outras palavras, uma organização vertical estabelece uma divisão vertical do trabalho, e reproduz, assim, a divisão entre trabalho de direção-subordinação e trabalho intelectual-manual, característico da estrutura de funcionamento das sociedades capitalistas. Não é por acaso que observamos a preocupação, nos escritos de Freire, com a participação horizontal dos agentes no trabalho educativo.

Registre-se, todavia, que participação horizontal não significa igualar educador e educando no processo educativo. Como vimos anteriormente, o educador é um "organizador necessário, é ensinante e um desafiador". A educação crítica, reconhecendo a desigualdade de distribuição do conhecimento, efeito da distribuição desigual de recursos e meios de produção, luta para diminuição de tal desigualdade. O educador crítico contribui para que as classes subalternas se apropriem do conhecimento produzido historicamente pela humanidade, conhecimento este que compreende a filosofia, a política, a economia, o direito, dentre outras áreas do saber. E também estimula a produção de conhecimento por parte deles. Mas isso é possível desvinculado das condições objetivas materiais? A resposta, certamente, é não. A pedagogia do oprimido é uma pedagogia eminentemente política, e não só do ponto de vista epistemológico, mas também pelo seu engajamento na luta política por condições 
materiais para que as classes oprimidas possam ter acesso à educação escolar. Por isso, dissemos que Paulo Freire não era indiferente à democracia e à cidadania burguesas. A partir das possibilidades estruturais (do regime democrático burguês), a pedagogia do oprimido é luta por direito, por reconhecimento do direito aos estudos das classes subalternas. Numa sociedade onde se constata o desajuste entre importância da educação e jornadas de trabalho extensas, a luta por tempo para os estudos se torna decisiva. A pedagogia do oprimido se revela assim como um luta política e educacional no interior da ordem, mas com vistas à derrubada dessa ordem. ${ }^{10}$

A liberdade é um conquista, diz Freire, e não uma doação, exige, necessita luta. "Libertação que não chegarão pelo acaso, mas pela práxis da busca; pelo conhecimento e reconhecimento da necessidade de lutar por ela”. (op. cit, p.17)

\section{Considerações finais}

No decorrer deste ensaio, procuramos evidenciar as tensões entre educação, política e emancipação, considerando os laços de necessidade e de possibilidade na relação entre esses termos. A partir das reflexões de Paulo Freire, procuramos mostrar que a tensão entre a educação e a emancipação se realiza mediante o posicionamento crítico e engajado dos agentes educacionais, uma vez que o elemento que os tensiona é o laço social. Podemos afirmar assim que é na busca de superar o estado de heteronomia e a situação de opressão que esses termos possíveis são atados na prática social dos oprimidos.

Consciente de que ninguém se liberta sozinho e de que a liberdade exige a transformação do mundo objetivo, a pedagogia do oprimido é uma pedagogia da práxis, da práxis humana coletiva. Em Pedagogia da esperança, Paulo Freire diz:

\footnotetext{
${ }^{10}$ A esse respeito, em Política e Educação, Paulo Freire assinala que quando Luiza Erundina se elegeu prefeita da cidade de São Paulo: "Uma das primeiras providências a serem tomadas, sem ferir o espírito da lei, foi reorientar as opções embutidas no orçamento realizado pelo governo a que sucedíamos. Opções obviamente em que pouco havia que dissesse respeito a interesses diretos das classes populares.

Enquanto sofríamos um déficit escolar elevado a $60 \%$ das unidades da rede escolar em estado precário o orçamento que recebemos previa cifras astronômicas para o que se chama grandes obras. [...] Os viadutos eram prioritários, mas para servir às classes abastadas e felizes, com repercussão também adjetiva para as classes populares. As escolas eram prioritárias para as classes populares, com repercussão adverbial para as classes ricas. [...] Estamos defendendo apenas o direito de milhares de crianças estudarem como prioridade ao conforto de quem já o tem em excesso[...]Eleito um governo de corte democrático, é possível rever, refazer medidas que aprimorem o processo de democratização da escola pública. É possível o empenho de ir tentando começar ou aprofundar o esforço de, tornando a escola pública menos má, fazê-la popular também. Foi a esse empenho que chamei durante o tempo em que fui Secretário da Educação da administração de Luiza Erundina de 'mudança da cara da escola'.[...] Ganhar as eleições da cidade de São Paulo não significava inaugurar no dia seguinte o socialismo no país." (1997b, p.51)
} 


\begin{abstract}
Libertação e opressão [..] não se acham inscritas, uma e outra, na história, como algo inexorável. Da mesma forma a natureza humana, gerando-se na história, não tem inscrita nela o ser mais, a humanização, a não ser como vocação de que o seu contrário é distorção na história [...] Homens e mulheres, ao longo da história, vimonos tornando animais deveras especiais: inventamos a possibilidade de nos libertar na medida em que nos tornamos capazes de nos perceber como seres inconclusos, limitados, condicionados, históricos. Percebendo, sobretudo, também, que a pura percepção da inconclusão, da limitação, da possibilidade, não basta. É preciso juntar a ela a luta política pela transformação do mundo. A libertação dos indivíduos só ganha profunda significação quando se alcança a transformação da sociedade. (FREIRE, 1997b, p. 100, grifo nosso).
\end{abstract}

Para Paulo Freire, a "superação autêntica" da contradição opressores-oprimidos se situa para além da simples troca de lugar entre agentes (situação na qual se verificaria apenas a passagem dos indivíduos de um polo a outro), seja nas relações econômicas quanto nas relações de dominação-subordinação políticas e ideológicas. Como exemplo assinala que:

Raros são os camponeses que, ao serem 'promovidos' a capatazes, não se tornam mais duros opressores de seus antigos companheiros do que o patrão mesmo. Poderse-ia dizer - e com razão - que isto se deve ao fato de que a situação concreta, vigente, de opressão, não foi trasformada. E que, nesta hipótese, o capataz, para assegurar seu posto, tem de encarnar, com mais dureza ainda, a dureza do patrão". (1987, p.18)

Daí Paulo Freire ser um leitor de Marx, para quem a alteração das circunstâncias materiais que constrangem os homens e a emancipação humana são vias que caminham juntas. Ou seja, somente com o fim da propriedade privada dos meios de produção e com a sua apropriação/controle pelas classes subalternas é que a sociedade burguesa (com suas classes e seus antagonismos de classe) será superada, e então, somente então, poderá surgir uma "associação em que o livre desenvolvimento de cada um é o pressuposto para o livre desenvolvimento de todos" (MARX e ENGELS, 2008, p. 46).

\title{
Referências Bibliográficas
}

FREIRE, Paulo. Pedagogia da indignação - cartas pedagógicas e outros escritos. São Paulo: Editora UNESP, 2000.

Cortez, 1997a.

A importância do ato de ler: em três artigos que se completam. São Paulo: Política e educação: ensaios. São Paulo: Cortez, 1997b.

Pedagogia da esperança. Um reencontro com a pedagogia do oprimido. São Paulo: Paz e Terra, 1997c.

. Pedagogia da Autonomia. São Paulo: Paz e Terra, 1996. 
Pedagogia do Oprimido. Rio de Janeiro: Paz e Terra, 1987.

- Conscientização - Teoria e Prática da Libertação - Uma Introdução ao Pensamento de Paulo Freire. São Paulo: Cortez \& Moraes, 1979a.

. Educação e mudança. 28 ed. São Paulo: Paz e Terra, 1979b.

MARX, Karl. Manuscritos econômico-filosóficos. São Paulo: Boitempo Editorial, 2008.

. Para a questão judaica. São Paulo: Expressão Popular, 2009.

MARX, K., ENGELS, F. Manifesto do Partido Comunista. São Paulo: Expressão Popular, 2008.

A ideologia Alemã. Tradução Rubens Enderle, Nélio Schneider e Luciano Cavini Martorano. São Paulo: Boitempo, 2007.

SAVIANI, Dermeval. Escola e Democracia. 4aed. São Paulo: Autores Associados, 19--. 